\title{
Polymorphisms of Platelet Glycoprotein Receptors and Cell Adhesion Molecules in Fetuses with Fetal Growth Restriction and Their Mothers As Detected with Pyrosequencing
}

\author{
MARIA SIMOU ${ }^{1}$, EVAGGELIA KOUSKOUNI ${ }^{2}$, NIKOLAOS VITORATOS ${ }^{1}$, \\ EMMANUEL ECONOMOU ${ }^{2}$ and GEORGE CREATSAS ${ }^{1}$ \\ ${ }^{1}$ Second Department of Obstetrics and Gynecology, Medical School, Aretaieio Hospital, \\ National and Kapodistrian University of Athens, Athens, Greece; \\ ${ }^{2}$ Laboratory of Therapeutic Individualization, Second Department of Obstetrics and Gynaecology, \\ National and Kapodistrian University of Athens, Medical School, Aretaieio Hospital, Athens, Greece
}

\begin{abstract}
Background: Vascular thrombotic tendency may lead to fetal growth restriction (FGR). Altered platelet function and genetic heterogeneity may play a role in this procedure. We investigated whether maternal or fetal genotypic frequencies of genes polymorphisms for certain platelet receptor and cell adhesion molecules are altered in FGR. Materials and Methods: We compared the maternal and fetal genotypic frequencies of single nucleotide polymorphisms (SNPs) in four genes coding for platelet receptors and cell adhesion molecules [integrin alpha subunit 2 (ITGA2)C807T integrin subunit beta 3(ITGB3) T1565C, platelet cell adhesion protein 1 (PECAM1) CTG-GTG and selectin P(SELP )A/C]. A total of 32 fetuses with fetal growth restriction and their mothers were matched with 18 normal controls. Using maternal venous blood and umbilical cord blood samples, nucleotide sequences were determined from pyrograms. Genotypic frequencies were calculated and analyzed using appropriate tests and logistic regression. Results: There was no statistical difference in the proportion of heterozygotes or homozygotes for any of the genotypic frequencies between FGR and control groups in mothers or fetuses. Conclusion: Our study demonstrated no association of maternal or fetal ITGA2 C807T SNP, ITGB3 T1565C SNP, PECAM1 CTG GTG and SELP A/C polymorphisms with FGR.
\end{abstract}

This article is freely accessible online.

Correspondence to: Maria Simou, MD, Second Department of Obstetrics and Gynaecology, National and Kapodistrian University of Athens, Aretaieio Hospital, Vasilisis Sofias 76, Athens Greece. Tel: +30 2107286353, +30 2107217835, Fax: +30 2107233330, e-mail: maria.simou@ymail.com

Key Words: FGR, platelet glycoproteins, SNPs, pyrosequencing.
Fetal growth restriction (FGR) accounts for $5-10 \%$ of all pregnancies, increasing perinatal morbidity and mortality (1). It is a common clinical problem and most commonly refers to fetuses with an estimated weight below the 10th, 5th or 3rd percentile based on biometric measurements on ultrasound or to infants born with birth weight less than the above percentiles for their gestational age $(2,3)$.

Among fetal, placental and maternal factors contributing to FGR, placental insufficiency is the major risk factor. This insufficiency can result from placentation disorders, as well as from other risk factors such as smoking and thrombotic tendency (4).

FGR as well as pre-eclampsia are associated with abnormal trophoblastic invasion leading to altered vascular placental remodeling. Several studies tried to suggest an association between platelet function and FGR. Moreover, an established relationship between FGR and later onset infantile and maternal cardiovascular disease has been shown $(5,6)$, with cardiovascular disease being linked in general with abnormal platelet function based on altered platelet aggregation $(7,8)$. Keeping these links in mind and considering the possible reduction in pre-eclampsia and FGR with the use of aspirin, focus on platelets, their receptors and platelet function has been carried out $(4,6)$.

Gene polymorphisms of platelet glycoproteins have been investigated as possible risk factors of prothrombotic tendency but their role in genetic influence on atherothrombosis remains unproven and conflicting. Thrombus formation mediated by platelets on a damaged vessel involves platelet adhesion, platelet activation and platelet-platelet cohesion (platelet aggregation) and thereafter continuing platelets deposition after vessel injury. Platelet glycoprotein receptors and adhesive ligands interact in order for platelet thrombus to be formed, while some adhesive platelet glycoproteins take part in platelet- 
leukocyte interaction and play significant role in inflammation that couples vascular injury and thrombosis. Many of the genes for glycoprotein receptors contain single nucleotide polymorphisms (SNPs), quite commonly in the general population. These polymorphisms may alter receptor function, and therefore alter the tertiary structure of the receptor and finally modify platelet adhesive capacity. This happens because a nucleotide polymorphism that occurs in a gene regulatory region can change the level of expression of the receptor on the surface of platelets.

ITGA2 and ITGB3, are platelet glycoprotein receptors that belong in the family of integrins. ITGA2 plays an important role in platelet adhesion and activation by binding to collagen, while ITGB3 binds fibrinogen after activation of platelets with thrombin, ADP and other agonists, being an important receptor for platelet aggregation. Activation of platelets results in the expression of platelet surface Pselectin, which plays a functional role in platelet-leukocyte interaction. P-Selectin functions as a cell adhesion molecule on the surface of activated endothelial cells which line the inner surface of blood vessels, and on activated platelets. Platelet endothelial cell adhesion molecule (PECAM1) is found on the surface of platelets, monocytes, neutrophils, and some types of T-cells, and makes up a large portion of endothelial cell intercellular junctions. The protein is a member of the immunoglobulin superfamily and is likely involved in leukocyte transmigration, angiogenesis, and integrin activation.

A gap in the literature exists regarding the investigation of common polymorphisms in genes coding for ITGA2, ITGB3, P-selectin and PECAM1 simultaneously in mothers and fetuses in pregnancies complicated by FGR, which would give furher insight into the role of relevant fetal and maternal genotypic profile in adverse pregnancy outcome of growth restriction $(4,6,8)$.

The ITGA2 C807T polymorphism is in complete disequilibrium with another exonic polymorphism, G873A, and other SNPs located in adjoining introns $(9,10)$. ITGA2 is located on chromosome $5 q 23-31$. The $807 \mathrm{~T}$ allele is found in $35 \%$ of the Caucasian population. In contrast to the $807 \mathrm{C}$ variant, the $807 \mathrm{~T}$ allele has been linked to increased receptor density and increased collagen-induced platelet adhesion (10, 11), leading to atherothrombotic disease through modulation of inflammatory response to vascular insult.

ITGB3 subunit of IIb/IIIa receptor consists of two isoforms. This dimorphism is due to $1565 \mathrm{~T}>\mathrm{C}$ resulting in Leu33Pro amino acid substitution, found in $15 \%$ of Caucasians. This substitution evokes changes in the receptor that may provoke mild prothrombotic tendency (12).

PECAMI is important in the process of angiogenesis and transendothelial migration of leukocytes. The cytoplasmic domain of PECAMI is encoded by eight short exons prone to splicing, giving rise to different PECAMI isoforms, e.g. isoform $\Delta 15$ present in platelets having different $\mathrm{C}$-terminal sequence (13). Alterations in the PECAMI cytoplasmic domain by alternative splicing, PECAM1 phosphorylation, and changes in PECAMI expression levels are potential ways to modulate its adhesive properties. The most frequent polymorphism described is the CTG to GTG substitution found in codon 125 of domain 1, leading to the presence of Leu125 or Val125 allele (14).

Finally, P-selectin is also very important in the recruitment and aggregation of platelets at areas of vascular injury. In quiescent platelets, P-selectin is located on the inner wall of $\alpha$-granules. Platelet activation (through agonists such as thrombin, type II collagen and ADP) results in 'membrane flipping' where the platelet releases $\alpha$ - and dense granules and the inner walls of the granules are exposed on the outside of the cell. P-selectin then promotes platelet aggregation through platelet-fibrin and platelet-platelet binding. Patients with myocardial infarction show increased P-selectin mediated platelet-leukocyte adhesion, while the antiplatelet drug clopidogrel was shown to attenuate Pselectin expression occurring in atherosclerotic disease (15). Substitution SNPs such as Thr715Pro and Val640Leu in the SELP gene coding for P-selectin have been implicated as potential determinants of stroke (16).

Pregnancy is considered a hypercoaguable state, with increased thrombotic tendency, 5.5-times greater than normal non-pregnant controls (17). On the other hand, FGR poses a great risk for increased perinatal morbidity. Association with disorders in the hemostatic pathway has been proposed, as a possible etiological factor. Since platelet glycoprotein receptors and adhesion molecules play an important role in hemostatic pathway and thrombosis, we made the hypothesis that polymorphisms in ITGA2, ITGB3, PECAMI and SELP may be significant factors in pregnancies complicated by FGR. Therefore, we investigated four known polymorphisms in a prospective cross-sectional study both in mothers and fetuses in growth restricted pregnancies.

\section{Materials and Methods}

This prospective study was conducted on 58 women presenting for prenatal care and their fetuses at the Second Department of Obstetrics and Gynecology of the University of Athens. The study was approved by the local Institutional Review Board (4/30-042008, issue number 15) and Ethics Committee for Human Studies and all patients gave informed consent.

The sample population consisted of 32 fetuses with FGR with their mothers and 18 control fetuses appropriate for gestational age with their mothers. Six women from the FGR group did not deliver at our unit and two women refused blood sampling at delivery. Only singleton pregnancies were enrolled, while mothers and fetuses with known chromosomal or structural abnormality were left out of the study. Altogether 100 blood samples (50 pairs) were finally analyzed. 
Table I. Characteristics of fetal growth restriction (FGR) group ( $N=32$ mothers/fetuses) and the control group (N=18 mothers/fetuses).

\begin{tabular}{|c|c|c|c|}
\hline \multirow[b]{2}{*}{ Characteristic } & \multicolumn{2}{|c|}{ Group } & \multirow[b]{2}{*}{$p$-Value } \\
\hline & $\begin{array}{l}\text { Control } \\
\text { N (\%) }\end{array}$ & $\begin{array}{c}\text { FGR } \\
\text { N }(\%)\end{array}$ & \\
\hline Mean age (SD), years & $30.2(4.5)$ & $31.8(6.2)$ & $0.328^{S}$ \\
\hline \multicolumn{4}{|l|}{ Parity } \\
\hline 1 & $8(44.4)$ & $22(68.8)$ & $0.184^{\mathrm{F}}$ \\
\hline 2 & $8(44.4)$ & $6(18.8)$ & \\
\hline$>2$ & $2(11.1)$ & $4(12.5)$ & \\
\hline Mean gestational age (SD), weeks & $39.4(0.9)$ & $36.9(2.0)$ & $<0.001^{\mathrm{S}}$ \\
\hline \multicolumn{4}{|l|}{ Delivery } \\
\hline Cesarean section & $0(0)$ & $19(59.4)$ & $<0.001^{F}$ \\
\hline OVD & $1(5.6)$ & $1(3.1)$ & \\
\hline Vaginal & $17(94.4)$ & $12(37.5)$ & \\
\hline Mean birth weight (SD), g & $3361.4(276.0)$ & $2290.5(344.3)$ & $<0.001^{\mathrm{S}}$ \\
\hline \multicolumn{4}{|l|}{ Gender } \\
\hline Female & $11(61.1)$ & $19(59.4)$ & $0.904^{\mathrm{P}}$ \\
\hline Male & $7(38.9)$ & $13(40.6)$ & \\
\hline Median centile (IQR), \% & $48.5(31.0-70.0)$ & $4.0(2.0-7.5)$ & $<0.001$ MW \\
\hline \multicolumn{4}{|l|}{ Smoking during pregnancy } \\
\hline No & $15(83.3)$ & $21(65.6)$ & $0.181^{\mathrm{P}}$ \\
\hline Yes & $3(16.7)$ & $11(34.4)$ & \\
\hline Mean weight gain during pregnancy (SD), $\mathrm{kg}$ & $14.8(4.8)$ & $11.1(4.0)$ & $0.006^{\mathrm{S}}$ \\
\hline Mean postnatal centile (SD), $\%$ & - & $5.4(2.1)$ & \\
\hline
\end{tabular}

IQR:Interquartile range; OVD: operative vaginal delivery; SD: standard deviation. ${ }^{S}$ Student's $t$-test; FFisher's exact test; PPearson's $\chi^{2}$ test. MW Mann-Whitney test. Significant differences are shown in bold.

The definition of FGR for the purpose of the analysis included all participants with a prenatal diagnosis of estimated fetal weight $<10$ th centile based on the Hadlock formula (18), after serial scans, taking into account sonographic measurements of fetal biparietal diameter, head and abdominal fetal circumference and femoral length, with or without ultrasonographic signs of placental insufficiency (abnormal Doppler, decreased amniotic fluid) from 24 weeks' gestation and beyond. Growth restriction was confirmed at birth as being less than the 10th centile using customized birthweight centile charts (19). Results were compared with third trimester singleton control pairs (mother/fetus).

At delivery, maternal venous blood and fetal umbilical artery blood were collected in EDTA containing tubes and stored at $-20^{\circ} \mathrm{C}$ until DNA extraction.

Molecular analysis. Extraction of genomic DNA was carried out usingNucleoSpin ${ }^{\circledR}$ Blood Quick Pure Kit MACHEREY-NAGEL INC., Bethlehem, PA, USA, according to the manufacturer instructions.

Forward and reverse primers were used in order to amplify the region surrounding each SNP for each gene. We used the following forward and reverse polymerase chain reaction (PCR) primers: ITGB3 polymorphism at exon 3 T1565C (L33P): 5'-TGCTC CAATGTACGGGGTAA-3', and 5'-CCTCACTCACTGGGAACTC GA-3'; ITGA2 at exon 7 C807T: 5'-CAGCCCATTAATAAATGTC TCCTC-3' and 5'-AGCACCAAAACTTACCTTGCATAT-3'; PECAM1 at ex on 3 L125V CTG to GTG: 5'-TCCTGAAGTCCGG ATCTATGA-3' and 5'-TTATTCACGCCACTGTGTGC-3'; SELP:
5'-TGAAAATTGTACCTTGGCAGGTTG-3' and 5'-CAACCTCTG GGGAAACTTCAGTTA-3'. PCR was performed in a $25 \mu \mathrm{l}$ reaction mix containing $2 \mu \mathrm{l}$ of extracted DNA, $21 \mu \mathrm{l}$ distilled water, $1 \mu \mathrm{l}$ forward and $1 \mu \mathrm{l}$ reverse primer. The sequencing primers that evolved were GGGGACCTCACAAACA for ITGA2, GCTCCTGT CTTACAGGC for ITGB3, CACCTTCCACCAACA for PECAMI and AGGTTGGCACGGTA for SELP, respectively. All PCR products were pyrosequenced by the Qiagen PYROMARK Q24 pyrosequencing system (QIAGEN Instruments AG, Hombrechtikon, Switzerland), sequencing primers were hybridized to a singlestranded polymerase chain reaction-amplified DNA template. As a result of the whole process, the nucleotide sequence was determined from a signal peak in pyrograms. Genotypes were designated as wild-type (without SNP), allele heterozygous and homozygous accordingly for each polymorphism studied.

Statistical analysis. Continuous variables are presented with mean and standard deviation (SD) or with median and interquartile range (IQR). Quantitative variables are presented with absolute and relative frequencies. Student's $t$-tests were used for the comparison of mean values. Mann-Whitney tests were used in order to compare median values. For the comparison of the proportions of heterozygotes and homozygotes, chi-square and Fisher's exact tests were used accordingly. Fisher's exact tests were also used to confirm Hardy-Weinberg equilibrium. Logistic regression analysis was used to explore if the likelihood of a mother being heterozygous or homozygous was associated with greater likelihood of having a heterozygous or homozygous fetus after adjusting for 
the group (FGR or control). The interaction of the group (FGR or control) with the presence of alleles was tested in order to explore if the hypothesized associations were significantly different between the two groups. Odds ratios with $95 \%$ confidence intervals are shown from the results of the logistic regression analyses. All reported $p$-values are two-tailed. Statistical significance was set at $p<0.05$ and analyses were conducted using SPSS statistical software (version 17. 0; SPSS Inc., Chicago, IL, NY, USA).

\section{Results}

The mean age of the mothers was 31.8 years ( $\mathrm{SD}=6.2$ years) for the FGR group and 30. 2 years ( $S D=4.5$ years) for the control group. Characteristics of the two groups are presented in Table I. As expected, gestational age, birth weight, centile and weight gain during pregnancy were significantly greater in the control group compared to the FGR group. In addition, the proportion of cesarean sections was significantly greater in the FGR group.

The proportion of heterozygotes and homozygotes for the study genotypes in FGR and control groups (mothers and fetuses) are shown in Table II. There was no significant difference in the proportion of heterozygotes and homozygotes in fetuses and mothers for any of the genotypes between the FGR and control groups. All genotypes were found to be in Hardy-Weinberg equilibrium and no substantial linkage disequilibrium was observed $(p>0.05)$.

Table III presents the distribution of study genotype combinations in FGR and control groups. The most frequent mutation combinations both in mothers and fetuses were ITGA2 C807T with PECAM1 CTG-GTG and ITGB3 T1565C with PECAM1 CTG-GTG. The majority of study genotype combinations were not significantly different between FGR and control group both in mothers and their fetuses. Concerning fetuses, the ITGB3 T1565C/SELP A/C and ITGB3 T1565C/PECAM1 CTG-GTG/SELP A/C combinations were more frequent in the control group compared to FGR (16.7\% vs. 0\%,p=0.042). No significant differences between FGR and control groups both in mothers and their fetuses were found when the study genotype combinations of homozygotes were considered. When logistic regression analysis was conducted in order to explore if the likelihood of a mother being heterozygous or homozygous was associated with a greater likelihood of having a heterozygous or homozygous fetus, a strong association between mothers and fetuses for all genotypes (Table IV). Specifically, after adjusting for the group (FGR or control), mothers carrying the $\mathrm{T}$ allele for ITGA2 C807T had 5. 65 times greater likelihood of having a fetus carrying the $\mathrm{T}$ allele. Similarly, mothers carrying the $\mathrm{C}$ allele for ITGB3 T1565C had 5.65-times greater likelihood of having a fetus carrying $\mathrm{C}$ for ITGB3 $\mathrm{T} 1565 \mathrm{C}$. Mothers carrying PECAM1 GTG had almost six-fold greater likelihood of having a fetus carrying GTG for PECAM1 (OR=5.94, 95\%
Table II. Distribution of study genotypes in the fetal growth restriction (FGR) and control groups.

\begin{tabular}{|c|c|c|c|}
\hline \multirow[b]{2}{*}{ Genotype } & \multicolumn{2}{|c|}{ Group } & \multirow[b]{2}{*}{$p$-Value } \\
\hline & $\begin{array}{l}\text { Control } \\
\mathrm{N}(\%)\end{array}$ & $\begin{array}{c}\text { FGR } \\
\mathrm{N}(\%)\end{array}$ & \\
\hline \multicolumn{4}{|l|}{ Mothers } \\
\hline \multicolumn{4}{|l|}{ ITGA2 C807T } \\
\hline Absence & $9(50.0)$ & 15 (46.9) & \multirow[t]{3}{*}{$0.588^{\mathrm{F}}$} \\
\hline Heterozygous & $9(50.0)$ & $14(43.8)$ & \\
\hline Homozygous & $0(0.0)$ & $3(9.4)$ & \\
\hline \multicolumn{4}{|l|}{ ITGB3 T1565C } \\
\hline Absence & $13(72.2)$ & $20(62.5)$ & \multirow[t]{3}{*}{$0.213^{\mathrm{F}}$} \\
\hline Heterozygous & $3(16.7)$ & $11(34.4)$ & \\
\hline Homozygous & $2(11.1)$ & $1(3.1)$ & \\
\hline \multicolumn{4}{|c|}{ PECAM1 CTG-GTG } \\
\hline Absence & $4(22.2)$ & $12(37.5)$ & \multirow[t]{3}{*}{$0.096^{\mathrm{P}}$} \\
\hline Heterozygous & $8(44.4)$ & $17(53.1)$ & \\
\hline Homozygous & $6(33.3)$ & $3(9.4)$ & \\
\hline \multicolumn{4}{|l|}{$S E L P \mathrm{~A} / \mathrm{C}$} \\
\hline Absence & $16(88.9)$ & $27(84.4)$ & \multirow[t]{3}{*}{$1.000^{\mathrm{F}}$} \\
\hline Heterozygous & $2(11.1)$ & $5(15.6)$ & \\
\hline Homozygous & $0(0.0)$ & $0(0.0)$ & \\
\hline \multicolumn{4}{|l|}{ Fetuses } \\
\hline \multicolumn{4}{|l|}{ ITGA2 C807T } \\
\hline Absence & $11(61.1)$ & $14(43.8)$ & \multirow[t]{3}{*}{$0.575^{\mathrm{F}}$} \\
\hline Heterozygous & $6(33.3)$ & $14(43.8)$ & \\
\hline Homozygous & $1(5.6)$ & $4(12.5)$ & \\
\hline \multicolumn{4}{|l|}{ ITGB3 T1565C } \\
\hline Absence & $9(50)$ & $21(65.6)$ & \multirow[t]{3}{*}{$0.279^{\mathrm{P}}$} \\
\hline Heterozygous & $9(50)$ & $11(34.4)$ & \\
\hline Homozygous & $0(0.0)$ & $0(0.0)$ & \\
\hline \multicolumn{4}{|c|}{ PECAM1 CTG-GTG } \\
\hline Absence & $6(33.3)$ & $14(43.8)$ & \multirow[t]{3}{*}{$0.392^{\mathrm{P}}$} \\
\hline Heterozygous & $7(38.9)$ & $14(43.8)$ & \\
\hline Homozygous & $5(27.8)$ & $4(12.5)$ & \\
\hline \multicolumn{4}{|l|}{ SELP A/C } \\
\hline Absence & $15(83.3)$ & $26(81.3)$ & \multirow[t]{3}{*}{$0.397^{\mathrm{F}}$} \\
\hline Heterozygous & $2(11.1)$ & $6(18.8)$ & \\
\hline Homozygous & $1(5.6)$ & $0(0.0)$ & \\
\hline
\end{tabular}

ITGA2: Integrin subunit alpha 2; ITGB3: integrin subunit beta 3; PECAM1: platelet cell adhesion protein 1; SELP: selectin P. FFisher's exact test; PPearson's $\chi^{2}$ test.

$\mathrm{CI}=1.59-22.1$ ), while mothers carrying SELP C had 10.13times greater odds for having a fetus also carrying SELP C. No significant interaction was found between the group (FGR or control) and the presence of genotype, indicating that the association of study genotypes between mothers and their fetuses was similar in both groups.

\section{Discussion}

In this study, we analyzed data regarding the fetal and maternal association of SNPs in ITGA2, ITGB3, SELP and PECAM1 genes with the risk of FGR development. No 
Table III. Distribution of study genotype combinations in fetal growth restriction (FGR) and control groups.

\begin{tabular}{|c|c|c|c|}
\hline \multirow[b]{2}{*}{ SNP } & \multicolumn{2}{|c|}{ Group } & \multirow[b]{2}{*}{$p$-Value } \\
\hline & $\begin{array}{l}\text { Control } \\
\mathrm{N}(\%)\end{array}$ & $\begin{array}{c}\text { FGR } \\
\mathrm{N}(\%)\end{array}$ & \\
\hline \multicolumn{4}{|l|}{ Mothers } \\
\hline \multicolumn{4}{|l|}{ ITGA2807T/ } \\
\hline \multicolumn{4}{|c|}{ ITGB31565C } \\
\hline Absence & $14(77.8)$ & $27(84.4)$ & $0.705^{\mathrm{F}}$ \\
\hline Presence & $4(22.2)$ & $5(15.6)$ & \\
\hline \multicolumn{4}{|c|}{ ITGA2807T/ } \\
\hline \multicolumn{4}{|c|}{ PECAM1 GTG } \\
\hline Absence & $12(66.7)$ & $21(65.6)$ & $0.941^{\mathrm{P}}$ \\
\hline Presence & $6(33.3)$ & $11(34.4)$ & \\
\hline \multicolumn{4}{|c|}{ ITGA2807T/SELP C } \\
\hline Absence & $17(94.4)$ & $31(96.9)$ & $1.000^{\mathrm{F}}$ \\
\hline Presence & $1(5.6)$ & $1(3.1)$ & \\
\hline \multicolumn{4}{|c|}{ ITGB3 1565C/ } \\
\hline \multicolumn{4}{|c|}{ PECAM1 GTG } \\
\hline Absence & $14(77.8)$ & $25(78.1)$ & $1.000^{\mathrm{F}}$ \\
\hline Presence & $4(22.2)$ & 7 (21.9) & \\
\hline \multicolumn{4}{|c|}{ ITGB3 $1565 \mathrm{C} /$} \\
\hline \multicolumn{4}{|c|}{$S E L P \mathrm{~A} / \mathrm{C}$} \\
\hline Absence & $17(94.4)$ & $30(93.8)$ & $1.000^{\mathrm{F}}$ \\
\hline Presence & $1(5.6)$ & $2(6.3)$ & \\
\hline \multicolumn{4}{|c|}{ PECAM1 CTG-GTG/ } \\
\hline \multicolumn{4}{|c|}{ SELP C } \\
\hline Absence & $16(88.9)$ & $30(93.8)$ & $0.612^{\mathrm{F}}$ \\
\hline Presence & $2(11.1)$ & $2(6.3)$ & \\
\hline \multicolumn{4}{|c|}{ ITGA2 807T/ITGB3 } \\
\hline \multicolumn{4}{|c|}{$1565 \mathrm{C} / P E C A M 1 \mathrm{GTG}$} \\
\hline Absence & $15(83.3)$ & $29(90.6)$ & $0.654^{\mathrm{F}}$ \\
\hline Presence & $3(16.7)$ & $3(9.4)$ & \\
\hline \multicolumn{4}{|c|}{$I T G A 2807 \mathrm{~T} / I T G B$} \\
\hline \multicolumn{4}{|c|}{$31565 \mathrm{C} / S E L P \mathrm{C}$} \\
\hline Absence & $17(94.4)$ & $32(100)$ & $0.360^{\mathrm{F}}$ \\
\hline Presence & $1(5.6)$ & $0(0.0)$ & \\
\hline \multicolumn{4}{|c|}{ ITGA2807T/PECAM1 } \\
\hline \multicolumn{4}{|c|}{$\mathrm{GTG} / S E L P \mathrm{C}$} \\
\hline Absence & $17(94.4)$ & $32(100)$ & $0.360^{\mathrm{F}}$ \\
\hline Presence & $1(5.6)$ & $0(0.0)$ & \\
\hline \multicolumn{4}{|c|}{ ITGB31565C/PECAM1 } \\
\hline \multicolumn{4}{|c|}{$\mathrm{GTG} / S E L P \mathrm{C}$} \\
\hline Absence & $17(94.4)$ & $30(93.8)$ & $1.000^{\mathrm{F}}$ \\
\hline Presence & $1(5.6)$ & $2(6.3)$ & \\
\hline \multicolumn{4}{|c|}{ ITGA2 807T/ITGB3 } \\
\hline $1565 \mathrm{C} / P E C$ & & & \\
\hline GTG/SELP & & & \\
\hline Absence & $17(94.4)$ & $32(100)$ & $0.360^{\mathrm{F}}$ \\
\hline Presence & $1(5.6)$ & $0(0.0)$ & \\
\hline
\end{tabular}

significant differences were found between mothers and fetuses, individually and jointly in the genotypic frequencies between FGR cases and controls. Same results were conducted for combinations of genotypes.

\begin{tabular}{|c|c|c|c|}
\hline \multirow[b]{2}{*}{ SNP } & \multicolumn{2}{|c|}{ Group } & \multirow[b]{2}{*}{$p$-Value } \\
\hline & $\begin{array}{l}\text { Control } \\
\mathrm{N}(\%)\end{array}$ & $\begin{array}{c}\text { FGR } \\
\text { N (\%) }\end{array}$ & \\
\hline \multicolumn{4}{|l|}{ Fetuses } \\
\hline \multicolumn{4}{|c|}{ ITGA2 807T/ } \\
\hline \multicolumn{4}{|c|}{ ITGB31565C } \\
\hline Absence & $16(88.9)$ & $28(87.5)$ & \multirow[t]{2}{*}{$1.000^{\mathrm{F}}$} \\
\hline Presence & $2(11.1)$ & $4(12.5)$ & \\
\hline \multicolumn{4}{|c|}{ ITGA2807T/ } \\
\hline \multicolumn{4}{|c|}{ PECAM1 GTG } \\
\hline Absence & $13(72.2)$ & $22(68.8)$ & \multirow[t]{2}{*}{$0.797^{\mathrm{P}}$} \\
\hline Presence & $5(27.8)$ & $10(31.3)$ & \\
\hline \multicolumn{4}{|c|}{ ITGA2807T/SELP C } \\
\hline Absence & $18(100)$ & $29(90.6)$ & \multirow[t]{2}{*}{$0.544^{\mathrm{F}}$} \\
\hline Presence & $0(0.0)$ & $3(9.4)$ & \\
\hline \multicolumn{4}{|c|}{$I T G B 31565 \mathrm{C} /$} \\
\hline \multicolumn{4}{|c|}{ PECAM1 GTG } \\
\hline Absence & $10(55.6)$ & $25(78.1)$ & \multirow[t]{2}{*}{$0.095^{\mathrm{P}}$} \\
\hline Presence & $8(44.4)$ & 7 (21.9) & \\
\hline \multicolumn{4}{|c|}{$I T G B 31565 \mathrm{C} / S E L P \mathrm{C}$} \\
\hline Absence & $15(83.3)$ & $32(100)$ & \multirow[t]{2}{*}{$0.042^{\mathrm{F}}$} \\
\hline Presence & $3(16.7)$ & $0(0.0)$ & \\
\hline \multicolumn{4}{|c|}{ PECAM1 GTG/SELP C } \\
\hline Absence & $15(83.3)$ & $31(96.9)$ & \multirow[t]{2}{*}{$0.127^{\mathrm{F}}$} \\
\hline Presence & $3(16.7)$ & $1(3.1)$ & \\
\hline \multicolumn{4}{|c|}{ ITGA2 807T/ITGB3 } \\
\hline \multicolumn{4}{|c|}{$1565 \mathrm{C} / P E C A M 1 \mathrm{GTG}$} \\
\hline Absence & $16(88.9)$ & $30(93.8)$ & \multirow[t]{2}{*}{$0.612^{\mathrm{F}}$} \\
\hline Presence & $2(11.1)$ & $2(6.3)$ & \\
\hline \multicolumn{4}{|c|}{ ITGA2807T/ITGB } \\
\hline \multicolumn{4}{|c|}{$31565 \mathrm{C} / S E L P \mathrm{~A} / \mathrm{C}$} \\
\hline Absence & $18(100)$ & $32(100)$ & \multirow[t]{2}{*}{$* *$} \\
\hline Presence & $0(0.0)$ & $0(0.0)$ & \\
\hline ITGA2C 807 & & & \\
\hline CTG-GTG/s & & & \\
\hline Absence & $18(100)$ & $32(100)$ & $* *$ \\
\hline Presence & $0(0.0)$ & $0(0.0)$ & \\
\hline ITGB31565 & & & \\
\hline CTG-GTG/s & & & \\
\hline Absence & $15(83.3)$ & $32(100)$ & $0.042^{\mathrm{F}}$ \\
\hline Presence & $3(16.7)$ & $0(0.0)$ & \\
\hline ITGA2807T & & & \\
\hline $31565 \mathrm{C} / P E$ & & & \\
\hline GTG/SELP & & & \\
\hline Absence & $18(100)$ & $32(100)$ & $* *$ \\
\hline Presence & $0(0.0)$ & $0(0.0)$ & \\
\hline
\end{tabular}

ITGA2: Integrin subunit alpha 2; ITGB3: integrin subunit beta 3; PECAM1: platelet cell adhesion protein 1; SELP: selectin P. FFisher's exact test; PPearson's $\chi^{2}$ test. **p-Value was not calculated because of no distribution. Significant differences are shown in bold.

Our results revealed that gestational age, birth weight, centile and weight gain during pregnancy were significantly greater in the control group compared to the FGR group, a finding reasonable and consistent with morbidity associated 
Table IV. Odds ratios (OR) and 95\% confidence interval (95\% CI) for the association of study genotypes between mothers and infants

\begin{tabular}{lcc}
\hline Genotype & OR $(95 \% \mathrm{CI})$ & $p$-Value \\
\hline ITGA2 807T vs. C & $5.65(1.64-19.48)$ & 0.006 \\
ITGB3 1565C vs. T & $5.83(1.54-22.03)$ & 0.009 \\
PECAM1 GTG $v$. CTG & $5.94(1.59-22.1)$ & 0.008 \\
SELP C $v$ s. A & $10.13(1.73-59.44)$ & 0.010 \\
\hline
\end{tabular}

ITGA2: Integrin subunit alpha 2; ITGB3: integrin subunit beta 3; PECAM1: platelet cell adhesion protein 1; SELP: selectin P.

with FGR and other studies. Lee et al. reported that the optimal time of delivery of late preterm FGR fetuses with abnormal Doppler scan (umbilical artery) is 35 weeks, weighing the risk of prematurity with adverse perinatal outcome (20). In our study, the mean gestational age at delivery was 36.9 weeks for the FGR group, with mean birth weight of 2,290 g, compared to 39.2 weeks and $3,361 \mathrm{~g}$, respectively for the controls. The higher mean delivery age in our study is possibly as a result of the fact that we did not leave fetuses small for dates, with growth less than the 10th centile but with normal Doppler until delivery out of our FGR group. Similar gestational age at delivery is described in the PORTO study, where IUGR pregnancies were enrolled as having estimated fetal weight $<10$ th centile (21). Mean age at delivery in that study was 37.8 weeks, with a mean birth weight of $2,495 \mathrm{~g}$. The rate of cesarean delivery was higher in FGR group in our study, as expected.

The strength of our study is that as far as we are aware this is the first study to simultaneously investigate mothers and fetuses for more than one genotype regarding polymorphisms in platelet receptors and associated molecules in FGR pregnancies. Previous studies have tried to investigate the association of such polymorphisms but only in maternal blood (22-26). Hillman et al. failed to demonstrate any association of glycoprotein $\mathrm{Ib}$ platelet alpha subunit (GPIBA) polymorphisms with conditions such as pre-eclampsia, intrauterine growth restriction and miscarriage in primigravidae (22). Other studies investigated polymorphisms in ITGA2 and ITGB3 as a risk factor for vascular thrombosis and pre-eclampsia; no significant role was found (24-26). On the contrary, O'Shaughnessy et al. revealed a positive association of ITGB3 $\mathrm{C}$ allele with pre-eclampsia in an East Anglian cohort of 356 affected women (23).

Similar simultaneous fetal and maternal genotypic frequency studies have been conducted, but for other factors such as major histocompatibility complex, class I, G 14b (HLA-G 14b) or venous thrombosis factors (V Leiden, prothrombin ) $(27,28)$. Pileri et al. described a positive association with fetal thrombophilia and IUGR, regarding factors of venous thromboembolism (28). None of relevant studies conducted the molecular analysis with pyrosequencing. PCR, electrophoresis, restriction analysis or simple sequencing have been the methods used in studies so far $(23,27-29)$. Pyrosequencing is an advanced molecular technological method which uses sequencing by synthesis approach: modified nucleotides are added and removed one at a time, with chemiluminescent signals produced after the addition of each nucleotide. Since we use pyrosequencing for research in our laboratory, investigating Kirsten rat sarcoma $(K R A S)$ and B-Raf protooncogene $(B R A F)$ mutations for individualized therapy, we decided to use it in the present study as well. The disadvantage of this method is the high cost and therefore this is the reason for the low numbers of cases and controls in our study, coupled with the low incidence of FGR among pregnancy populations. The latter sets the main limitation to our study/together with the lack of placental histological data of all FGR pregnancies.

A strong association between mothers and fetuses in regard to genotypes resulted from our study, both in cases and controls. Therefore there might be further interest in future studies in the pathogenesis of inherited thrombophilias, as to whether maternal thrombophilia is related to fetal inherited thrombophilia.

The etiology of adverse pregnancy outcomes such as FGR is complex, as well as the relationship among the many thrombosis-related outcomes. Nevertheless, we failed to demonstrate any positive association of fetal/maternal polymorphisms in ITGA2, ITGB3 PECAM1 and SELP with FGR as a possible prothrombotic risk factor. Future larger prospective studies investigating the contribution of such polymorphisms might give further insight into such complex adverse pregnancy outcomes such as FGR.

\section{References}

1 Bamfo JE and Odibo AO: Diagnosis and management of fetal growth restriction. J: Pregnancy 2011: 640715, 2011.

2 Robson SC, Martin WL and Morris RK: The investigation and management of the small-for-gestational-age fetus. Royal College of Obstetricians \& Gynaecologists 31: 1-34, 2014. Available at https://www.google.gr/url?sa=t\&rct=j\&q=\&esrc=s\& source $=$ web $\& c d=4 \& c a d=$ rja $\& u a c t=8 \& v e d=0$ ahUKEwjUnZnR36 jSAhVIVRQKHayABLcQFggvMAM\&url=https $\% 3 \mathrm{~A} \% 2 \mathrm{~F} \% 2 \mathrm{Fw}$ ww.gestation.net\%2FRCOG_Green_Top_-_SGA_2013.pdf\&usg $=$ AFQjCNF-4J49-FRdWRqojmsbSJj1F nKrOQ Last accessed 24/02/2017

3 Lausman A, Kingdom J, Maternal Fetal Medicine Committee, Gagnon R, Basso M, Bos H, Crane J, Davies G, Delisle MF, Hudon L, Menticoglou S, Mundle W, Ouellet A, Pressey T, Pylypjuk C, Roggensack A and Sanderson F: Intrauterine growth restriction: screening, diagnosis, and management. J Obstet Gynaecol Can 35: 741-757, 2013. 
4 Roberge S, Odibo AO and Bujold E: Aspirin for the prevention of pre-eclampsia and intrauterine growth restriction. Clin Lab Med 36(2): 319-329, 2016.

5 Manten GT, Sikkema MJ, Voorbij HA, Visser GH, Bruinse HW and Franx A: Risk factors for cardiovascular disease in women with a history of pregnancy complicated by pre-eclampsia or intrauterine growth restriction. Hypertens Pregnancy 26: 39-50, 2007.

6 Mylotte D, Foley D and Kenny D: Platelet function testing: methods of assesement and clinical utility. Cardiovasc Hematol Agents Med Chem 9: 14-24, 2011.

7 Trip MD, Cats VM, van Capelle FJ and Vreeken J: Platelet hyperreactivity and prognosis in survivors of myocardial infarction. N Engl J Med 322(22): 1549-1554, 1990.

8 Can MM, Kaymaz C, Can E, Tanboğa IH, Api O, Kars B, Ceren Tokgoz H, Turkyilmaz E, Akgun T, Sonmez K, Saglam M, Turan $\mathrm{C}$, Unal $\mathrm{O}$ and Serebruany V: Whole blood platelet aggregation failed to detect differences between pre-eclampsia and normal pregnancy. Platelets 21: 496-497, 2010.

9 Kunicki TJ, Kritzik M, Annis DS and Nugent DJ: Hereditary variation in platelet integrin alpha 2 beta 1 density is associated with two silent polymorphisms in the alpha 2 gene coding sequence. Blood 89: 1939-1943, 1997.

10 Kritzik M, Savage B, Nugent DJ, Santoso S, Ruggeri ZM and Kunicki TJ: Nucleotide polymorphisms in the a2 gene define multiple alleles that are associated with differences in platelet a2b1 density. Blood 92: 2382-2388, 1998.

11 Roest M, Sixma JJ, Wu YP, Ijsseldijk MJ, Tempelman M, Slootweg PJ, de Groot PG and van Zanten GH: Platelet adhesion to collagen in healthy volunteers is influenced by variation of both a2b1 density and Von Willebrand factor. Blood 96: 14331437, 2000.

12 Honda S, Honda Y, Bauer B, Ruan C and Kunicki TJ: The impact of three-dimensional structure on the expression of P1A alloantigens on human integrin b3. Blood 86: 234-242, 1995.

13 Newman PJ and Newman DK: Signal transduction pathways mediated by PECAM1: new roles for an old molecule in platelet and vascular cell biology. Arterioscler Thromb Vasc Biol 23: 953-964, 2013.

14 Chao NJ, Hiraki DD, Krishnaswamy S, Brown BW, Zehnder JL and Grumet FC: Polymorphism of adhesion molecule CD31 and its role in acute graft-versus-host disease N Engl J Med 334: 286-291, 1993.

15 Klinkhardt U, Bauersachs R, Adams J, Graff J, Lindhoff-Last E and Harder S: Clopidogrel but not aspirin reduces P-selectin expression and formation of platelet-leukocyte aggregates in patients with atherosclerotic vascular disease. Clin Pharmacol Ther 73: 232-241, 2003.

16 Reiner AP, Carlson CS, Thyagarajan B, Rieder MJ, Polak JF, Siscovick DS, Nickerson DA, Jacobs DR Jr. and Gross MD: Soluble P-selectin, SELP polymorphisms, and atherosclerotic risk in European-American and African-African young adults: the Coronary Artery Risk Development in Young Adults (CARDIA) Study. Arterioscler Thromb Vasc Biol 28(8): 1549-1555, 2008.

17 Grandone E, Margaglione M, Colaizzo D, D'Andrea G, Cappucci G, Brancaccio V and Di Minno G: Genetic susceptibility to pregnancy-related venous thromboembolism: roles of factor V Leiden, prothrombin G20210A, and methylenetetrahydrofolatereductase C677T mutations. Am J Obstet Gynecol 179: 1324-1328, 1998.
18 Hadlock FP, Harrist RB, Sharman RS, Deter RL and Park SK: Estimation of fetal weight with the use of head, body, and femur measurements-a prospective study. Am J Obstet Gynecol 151: 333-337, 1985.

19 https:/www. gestation. net/cc/about. htm. GROW centile calculator.

20 Lee VR, Pilliod RA, Frias AE,. Rasanen JP, Shaffer BL and Caughey AB: When is the optimal time to deliver late preterm IUGR fetuses with abnormal umbilical artery Dopplers? J Matern Fetal Neonatal Med 29(5): 690-695, 2016.

21 Unterscheider J, Daly S, Geary MP, Kennelly MM, McAuliffe FM, O’Donoghue K, Hunter A, Morrison JJ, Burke G, Dicker P, Tully EC and Malone FD: Optimizing the definition of intrauterine growth restriction: the multicenter prospective PORTO Study. Am J Obstet Gynecol 208: 290.e1-6, 2013.

22 Hillmann A, Shields DC, Fitzgerald DJ and Kenny D: Polymorphisms in glycoprotein (GP) lb alpha are not associated with adverse outcomes in primigravidae. J Obstet Gynaecol 20: 250-255, 2000.

23 O'Shaughnessy KM, Fu B, Downing S and Morris NH: Thrombophilic polymorphisms in pre-eclampsia: altered frequency of the functional $98 \mathrm{C}>\mathrm{T}$ polymorphism of glycoprotein IIIa. J Med Genet 38: 775-777, 2001.

24 Pegoraro RJ, Hira B, Rom L and Moodley J: Plasminogen activator inhibitor type 1 (PAI1) and platelet glycoprotein IIIa (PGIIIa) polymorphisms in Black South Africans with preeclampsia. Acta Obstet Gynecol Scand 82: 313-317, 2003.

25 Sucker C, Schmitz M, Hetzel GR, Grabensee B, MaruhnDebowski B and Ostojic L, Scharf RE and Zotz RB: Are prothrombotic variants of platelet glycoprotein receptor polymorphisms involved in the pathogenesis of thrombotic microangiopathies? Clin Appl Thromb Hemost 15: 402-407, 2009.

26 Podciechowski L, Dabrowska K, Nowakowska D, Bielak A and Wilczynski J: Polymorphism of the glycoprotein Ia and IIIa in the group of women in childbirth does not correlate with an increased risk of developing thrombosis. Neuro Endocrinol Lett 26: 789-794, 2005.

27 Mandò C, Pileri P, Mazzocco MI, Lattuada D, Zolin A, Plebani M, Massari M, Calabrese S, Milani S and Cetin I: Maternal and fetal HLA-G $14 \mathrm{bp}$ gene polymorphism in pregnancy-induced hypertension, pre-eclampsia, intrauterine growth restricted and normal pregnancies. J Matern Fetal Neonatal Med 29: 15091514, 2016.

28 Pileri P, Franchi F, Cetin I, Mandò C, Antonazzo P, Ibrahim B, Rossi $\mathrm{F}$ and Biguzzi E: Maternal and fetal thrombophilia in intrauterine growth restriction in the presence or absence of maternal hypertensive disease. Reprod Sci 17: 844-848, 2010.

29 Ozkan S, Sanhal CY, Yeniel O, ArslanAtes E, Ergenoglu M, Bınbır B, Onay H, Ozkınay F and Sagol S: Pregnancy-associated plasma protein A gene polymorphism in pregnant women with pre-eclampsia and intrauterine growth restriction. Kaohsiung $\mathbf{J}$ Med Sci 31: 518-522, 2015.
Received January 8, 2017

Revised February 23, 2017 Accepted February 28, 2017 